\title{
Editorial
}

\section{Farewell from the Editor: Some Reflections about the Past, the Present and the Future}

After long deliberations, I have decided to step down as editor of AJCEB. It is not a decision I have taken lightly - in fact I have considered it for the last six months. Being the editor of AJCEB has been very enjoyable, but it has also been a lot of hard work, not always visible to the outsider. The workload is not likely to diminish, as there are new challenges across the social sciences that are already affecting research and which, if unchecked, will strongly influence the quality of research and publishing. I will touch briefly on that below, after some more personal reflections. If you are interested in these challenges, I will discuss them in more detail in the near future in a separate paper.

On a private level the work as editor has started to seriously interfere with my desire for leisure, travel and long lunches. On the plus-side, the job has allowed me to keep in touch with old friends, although the need to make selections of what to publish and not to publish has not always served to maintain old relationships or cement new ones. There is also a source of satisfaction to have helped, in a small way to determine the direction of the development of the discipline. Against this is that we have become victims of our success. What started as a hobby a few hours each week is now a major undertaking. As I am rapidly approaching middle age, I think it is now time to leave it to a new team and concentrate instead on all the things that would be on my bucket list had I ever been organized enough to compile one. The number of unread books in my bookshelf is growing alarmingly, the paint and canvasses I bought years ago are staring accusingly at me every time I enter the spare room and the list of countries I like to visit is growing out of control. So, I am leaving. Thank you for having supported the journal so well for the last few years. I hope you will continue to do so in the future.

As I said, this was not an easy decision. When I retired from lecturing 15 years ago I did so with mixed emotions: joy mixed with happiness. This time, there is a bit of sadness mixed into the anticipations of a new phase of life. However, I have satisfied the targets I set for myself when I accepted the role as editor. We have gone from two issues per year to four. We now have close to 1000 registered users, we get more than 1000 hits per week and almost all of them result in downloads, the number of manuscripts submitted have gone from $1-2$ per month to more than 2 per week and our geographical coverage has been greatly expanded, now including even Antarctica among the more well-known centres of learning. We are now indexed by no less than nine organisations. We are cited at a rate of more than 200 per year which means that we have an impact factor although it will take some time until it will give a fair picture of the influence of the journal. Finally, we have in cooperation with UTS ePress modernized the manuscript centre and introduced things like DOI and plagiarism detection software - which unfortunately has proved its value already. All previous issues from our past as a printed journal have also been made accessible on line.

What is planned is, among other things, to tap in on the very rich information that is starting to become available at both the level of the journal and the individual papers, such as for instance the number of visits and from where, the number of downloads - currently running

Australasian Journal of Construction Economics and Building 2014. (C 2014 Göran Runeson. This is an Open Access article distributed under the terms of the Creative Commons Attribution 4.0 Unported (CC BY 4.0) License (https://creativecommons.org/licenses/by/4.0/), allowing third parties to copy and redistribute the material in any medium or format and to remix, transform, and build upon the material for any purpose, even commercially, provided the original work is properly cited and states its license.

Citation: Runeson G. 2014, 'Editorial - Farewell from the Editor: Some Reflections about the Past, the Present and the Future'. Australasian Journal of Construction Economics and Building, 14(4), i-iii, http://dx.doi.org/10.5130/ajceb.v14i4.i 
at very near the number of visits - and the number of citations to give authors the best possible picture of the impact of their efforts. This is part of the future of publishing and possible only for on-line publications.

The decision to leave was made easier as there is now a group of people that are more than capable of continuing the work, and who have new ideas and new perspectives to add to the future development of the journal. In particular, this includes the new editor, Imriyas Kamardeen who has been largely responsible for the last two issues without anyone noticing much. It also includes a team from UTS ePress and in particular Scott Abbott who has displayed enormous patience and skills to make me understand - almost - how the manuscript centre works. His job will be greatly simplified when he is dealing with Imriyas. All that remains really is to thank the people who have been directly supporting me over the five years and most of all, Dr Jin Woo as Assistant Editor and Associate Professor Rick Best as the convenor of the Management Committee, Cornelia Cronje, Gabrielle Gardiner and all the others from UTS ePress. I could not have done it without you.

That deals with the past, the present and the near future. What will be a real challenge in the medium to long term is developments in the very nature of scientific research. Over the five years of my involvement with the journal, there have been significant changes in the environment of research publications in general and AJCEB has been part of this change. Among other things, our rejection rate, like these of other major journals, has gone up from about 50 per cent to more than 80 . This is not a deliberate attempt to increase quality, nor has it on its own improved quality. Rather it has been in response to the implications of the push by universities to increase the number of research publications without doing anything to facilitate this obsession with numbers.

However, the real problem, hiding behind this rejection rate is the far more serious issue about the nature of research, which has started to corrupt the image of science as a search for truth. This has happened in response to the demand from universities for more publications - regardless of quality - and it has happened not only in Construction Management but across a wide range of biomedical and social sciences (loanidis, 2005; Estes, 2012; Altman, 2002; Trouble at the lab, 2013). The studies mentioned here do not refer to construction management specifically, and there has as yet been no discussion of research in Construction Management per se. However, there is no reason to believe that these problems are not equally or more prevalent in our discipline, and there are lots of reasons to believe that they may be more severe. The problems tend to be the worst in the social sciences and in applied research, and construction management is just that.

As part of the discussion of the current standards of research, thorough examinations of various social and bio-medical sciences have concluded that in the majority of published studies, the research or the statistical analysis is so poor that 80 per cent of the conclusions should be reversed. As an example, in a study of 55 manuscripts published in one respected journal, the authors found at least one error in 87 per cent of the cases (Šimundić \& Nikolac, 2009). This, of course, is after all errors identified by editors and reviewers would have been corrected.

An equally disturbing examination, quoted by Lehrer (2010) found that of various research studies identifying 432 genes as variables that control differences in disease risks between men and women, the vast majority had serious flaws and only one of the 432 research claims could be consistently replicated. In another study, where Amgen, an American drug company tried to replicate landmark studies in cancer research, they were able to reproduce the original result in only six studies of 53 , or 11 per cent of the studies despite including the original researchers in a quarter of the studies (Prinz, Schlange \& Asadullah 2011).

With figures like these, it is no wonder that the confidence in science is falling and that the equivalent of the flat earth theory are starting to appear again in some fields of science, as we have seen in particular in the discussion of climate change. 
There are complex reasons for this development, and no-one involved, be it researchers, reviewers, editors or the people who use numbers of papers to allocate research resources and jobs is free from blame. However, it is clear that even apart from the increased pressure for publications that forces people to publish before they are ready, there are three prominent factors, alone or in combination, that are at the bottom of the problem. They are: ignorance about the appropriate theoretical framework for the research; failure to understand or realise the implications of the methodology and, as Suddaby (2006) warns, use approaches like Grounded Theory as "... an excuse for the absence of methodology" and "interpreted as 'anything goes"' (p.640) and finally not understanding the meaning of the statistical analysis that is now so easy to generate.

This also gives us an idea about what we can do to mitigate the problem. We have to master our theories and learn to adapt models until they fit our needs, rather than reject them and try to develop substitutes. We have to learn the implications of different methodological approaches and finally, to learn the applicability and meaning of our statistical analyses. This amounts to training our researchers and in particular a better training of PhD students. Unless we do, we will ensure that the two quality control mechanisms of science that are supposed to weed out poor science - peer review and replication - do not work as intended. Rather they will, as they do now, continue to protect us from outside influences and thereby ensure mediocrity. This is, no doubt, where we are heading now. The most serious challenge for the future is to change direction.

Thanks again for supporting the journal and please continue to do so.

Göran Runeson

Adjunct Professor, University of Technology, Sydney

\section{References}

Altman, D.G. 2002, 'Poor quality medical research: what can journals do', Journal of the American Medical Association, 287 (21), 2765 - 2767. doi: http://dx.doi.org/10.1001/jama.287.21.2765

Estes, S. 2012, 'The myth of self-correcting science', The Atlantic, http:/www.theatlantic.com/health/print/2012/12/the-myth-of-self-correcting-science/266228/, accessed 21 Dec 2012.

Ioannidis J.P.A. 2005, 'Why most published research findings are false', PLoS Med, 2 (8), e124, accessed 12 Jan 2014. doi: http://dx.doi.org/10.1371/journal.pmed.0020124

Lehrer, J. 2010, 'The Truth Wears Off, Is there something wrong with the scientific method?', The New Yorker, Dec 13, http://cbbp.thep.lu.se/ henrik/mnxa09/Lehrer2010.pdf, accessed 4 Dec 2014

Prinz, F. Schlange, T \& Asadullah, K. 2011, 'Believe it or not: how much can we rely on published data on potential drug targets?', Nature Reviews Drug Discovery, 10 (712).

Šimundić A-M \& Nikolac, N. 2009, 'Statistical errors in manuscripts submitted to Biochemia Medica journal', Biochemia Medica, 19 (3), 294-300. doi: http://dx.doi.org/10.11613/BM.2009.028

Suddaby, R. 2006, 'From the editors: What Grounded Theory is not', Academy of Management Journal, 49 (4), $633-42$.

Trouble at the lab 2013, The Economist, 409 (8858), 20-23. 